\title{
Stereotactic vacuum-assisted breast biopsy: our experience and comparison with stereotactic automated needle biopsy
}

\author{
Tothova L, Rauova K, Valkovic L, Vanovcanova L, Lehotska V \\ 2nd Radiologic Clinic of Medical Faculty Comenius University and St. Elisabeth Oncology Institute, Bratislava, \\ Slovakia. lucia.tothova@gmail..com
}

\begin{abstract}
Objectives: To evaluate and compare the outcome of stereotactically guided percutaneous, directional, vacuum-assisted breast biopsy (VAB) with the outcome of those performed with 14-gauge automated gun. Methods: Between January 2008 and January 2011, altogether 257 stereotactic biopsies were performed in our institute; 193 with the 14-gauge automated needle and 64 with a directional, vacuum-assisted instrument. Patients with malignant or high risk lesions were encouraged to undergo an excisional biopsy. We evaluated and compared concordance between the biopsy results and subsequent examinations (surgical excision or follow up) for both methods.

Results: VAB demonstrated 57 (89\%) benign lesions, 2 (3\%) high risk and 5 (8\%) malignant lesions. We obtained post-bioptic mammographic or histological evaluation for altogether 51 lesions, with one (12.5\%) false negative case, one case of underestimation of borderline lesion, and no false positive cases. Clusters of microcalcifiation were completely removed in 18 lesions (28\%).

Conclusion: Vacuum-assisted biopsy outperformed the 14-gauge automated needle biopsy with a lower disease underestimation, sensitivity and false-negative rates; however these differences were not statistically significant due to small data files and relatively small number of identified malignant lesions in the vacuum-assisted biopsy group.

VAB completely removed significantly more clusters of microcalcifications in comparison to the automated needle biopsy, which significantly reduced the need for surgery in benign lesions (Tab. 7, Fig. 3, Ref. 32). Full Text in PDF www.elis.sk.

Key words: vacuum-assisted biopsy, breast lesions, mammographic, stereotactic.
\end{abstract}

The treatment and diagnosis of breast cancer have undergone a distinctive shift during the last 30 years. The trend has been toward earlier diagnosis, less invasive diagnostic procedures, and ultimately less mutilating curative surgical procedures.

In recent years, the effects of earlier diagnosis have led to an overall decreased mortality from breast cancer (1).

Increased public awareness together with improvements in mammography has led to earlier diagnosis of breast cancer, ideally in the stage of in situ changes.

The majority of women diagnosed with breast cancer are candidates for wide excision and radiation rather then mastectomy. Routine axillary dissection is being replaced by sentinel lymph node biopsy and selective axillary dissection.

The development of stereotactic biopsy enables to shift the diagnosis of breast cancer into histologic conclusion before definitive surgical treatment on an awaked patient.

Early stereotactic techniques were problematic and multiple studies demonstrated the risk of under sampling the lesions, which

2nd Radiologic Clinic of Medical Faculty Comenius University and St. Elisabeth Oncology Institute, Bratislava, Slovakia

Address for correspondence: L. Tothova, MD, 2nd Radiologic Clinic of Medical Faculty Comenius University and St. Elisabeth Oncology Institute, Heydukova 10, SK-812 50 Bratislava, Slovakia.

Phone: +421.911278007 lead to histologic underestimation and false negative results. A continuous spectrum of proliferative changes exists between $\mathrm{ADH}$, DCIS and microinvasive ductal carcinoma.

The diagnosis of atypical ductal hyperplasia and ductal carcinoma in situ, as the early stages of malignancy, have been discovered in many studies as underestimating the true extent of pathologic abnormality (2-5).

The early studies have demonstrated that the diagnosis of atypical ductal hyperplasia (ADH) by means of stereotactic breast biopsy with automated fourteen-gauge biopsy gun system has resulted in nearly equal odds that a coexisting malignant lesion will be missed $(6,7)$. Furthermore, when stereotactic breast biopsy with an automated needle device results in a diagnosis of ductal carcinoma in situ (DCIS), the odds are approximately one in five that a coexisting infiltrating ductal carcinoma will be missed $(6,8)$.

The difficulty to establishe a complete and accurate DCIS diagnosis with stereotactic breast biopsy was emphasized also by others. Berg (9) suggested that "microcalcifications typical of DCIS be excised directly surgically to avoid performance of an unnecessary procedure (stereotactic breast biopsy)." Similarly, others described difficulties in completely and accurately diagnosing ADH and DCIS lesions $(10,11)$.

Stereotactically guided vacuum- assisted biopsy (VAB) has brought many advantages in performing and outcomes in comparison to the stereotactic biopsy with the automated needle device. 
Stereotactically guided vacuum-assisted biopsy retrieves a greater amount of tissue, thus decreasing sampling error and resulting in a more accurate diagnosis. The bigger sample volume and continual sampling enables more accurate calcification retrieval.

Multiple studies have demonstrated that the histological underestimation rate is lower for the 11-gauge or 14-gauge vacuum-assisted device (12-14) and fewer repeated biopsies are needed (15).

However, some studies still indicate a persistent underestimation of ADH diagnosed with 11-gauge vacuum-assisted device (2, $16,17)$. The study of Brem and co-workers reported a histological underestimation of carcinoma in $25 \%$ samples.

The purpose of this study was to evaluate and compare the outcome of stereotactically guided percutaneous, directional, vacuum-assisted breast biopsy with the outcome of those performed with 14-gauge automated gun.

To determine whether the outcomes of steroetactic biopsies performed by the two methods differ, we compared the histological entities found; the rate of missed cancer; the rate of cancer underestimation; complication rates; and the need for a second biopsy, both immediate and delayed.

\section{Materials and methods}

Between January 2008 and January 2011, altogether 257 stereotactic biopsies were performed in our institute. Stereotactic biopsy was performed with 14-gauge automated needle device (Magnum) in 193 lesions and with two types of directional, vacuum-asssisted instrument in 64 lesions (Ethicon Endo Surgery Mammotome, Johnson \& Johnson 2003, USA with 11-gauge vacuum-assisted probe until September 2010 and Suros ATEC Breast Biopsy and Excision System, Hologic, 2010, USA with 9-gauge vacuum-assisted probe from October 2010).

Until June 2010, the selection of vacuum-assisted biopsy was restricted within indication criteria set by a health insurance company to sampling only microcalcifications of benign or semimalignant mammographic appearance. As a result, an uneven patient distribution for both methods existed with more malignant lesions in the group of patients who underwent stereotactic automated needle biopsy.

For a stereotactic navigation, the mammographic system Mammomat 3000, Nova, Siemens, GE, 2006, with a digital stereotactic guidance was used in combination with the dedicated reclinable mammography chair. All biopsies were performed with the patient in an upright, sitting position. Core biopsy specimens were sampled by standard pathologic techniques. After each biopsy, a pathology report from the core biopsy sample was reviewed by the responsible radiologist before management recommendations were made. Any patient (except one in whom the surgery was contradicted) who was found to have $\mathrm{ADH}$, atypical lobular hyperplasia (ALH), lobular carcinoma in situ (LCIS) or DCIS went on to needle localization and excisional biopsy. In one patient with a low grade DCIS, the surgery was contradicted because of serious clinical condition and the biopsy was performed mainly to acquire imunohistochemical profile. Patients with palpable breast masses or axillary lymfadenopathy were not included in the current study.
The patient's age at the time of stereotactic breast biopsy, the basic mammographic lesion type (mass v. microcalcificatins), the lesion palpability and the therapeutic surgery performed after a stereotactic breast biopsy were recorded for both, automated needle and directional, vacuum-assisted procedures.

The pathology reports from the core biopsies were reviewed to determine the histological entities. Malignant entities included invasive carcinoma and ductal carcinoma in situ. High-risk lesions included radial scar and atypical ductal and lobular hyperplasia. Benign lesions included specific diagnosis, such as fibroadenoma or papilloma and nonspecific processes, such as fibrocystic change, apocrine metaplasis, adenosis and other.

Cases were considered as an underestimation if either atypical ductal hyperplasia diagnosed at stereotactic biopsy was found to be carcinoma at surgery or ductal carcinoma in situ diagnosed at biopsy was upgraded to invasive carcinoma at surgery. Cases were considered false-negative if carcinoma was found at surgery after core biopsy had shown benign results.

The usual follow-up protocol was a 6-month interval for benign lesions. For cases undergoing an imaging follow-up, subsequent mammography, sonography or MRI reports were reviewed. Follow-up information was available for 67 (75\%) of 89 lesions biopsied with stereotactic 14-gauge automated needle biopsy without a subsequent surgery. In one case with benign histological findings after the stereotactic automated needle biopsy, the second biopsy with vacuum assisted device was performed proving DCIS This case was excluded from the follow-up analysis. Follow-up information was available for altogether 41 (76\%) of 55 lesions biopsied with the vacuum-assisted device, without a subsequent operation.

The group biopsied with the 14-gauge automated gun was compared to the group biopsied with the 11-gauge stereotactic vacuum-assisted device for the following parameters examined: histological entities found on stereotactic biopsy, number of missed cancers, sensitivity and specificity, rate of histological underestimation and complications. Statistical associations were determined with chi-square analyses (StatCalc; version 7.1.2), with statistically significant differences assumed when $\mathrm{p}$ was lower then 0.05 .

\section{Results}

An automated needle biopsy and directional, vacuum-assisted biopsy were performed in comparable populations of patient and lesions. No statistically significant differences were detected between an automated needle biopsy and a directional, vacuumassisted biopsy in parameters of patient age at biopsy, percentage of lesions characterized by microcalcifications and lesion palpability (Tab. 1). Statistically significant difference was detected between the number of breast-conserving surgeries performed after the automated needle biopsy and the vacuum-assisted biopsy, with more therapeutic surgeries performed after the stereotactic automated needle biopsy.

The histological diagnoses of the stereotactic needle and vacuum-assisted biopsies are provided in Table 2. The histological diagnoses were similar for the two groups ( $p>0.3$, not significant). 
Tab. 1. Comparison of automated needle and directional, vacuum-assisted biopsy data across four patient and lesion parameters.

\begin{tabular}{|c|c|c|c|c|}
\hline Biopsy & $\begin{array}{c}\text { Average } \\
\text { Patient Age }\end{array}$ & $\begin{array}{c}\text { Lesions with } \\
\text { Microcalcifications* (\%) }\end{array}$ & $\begin{array}{l}\text { Palpable Lesions } \\
(\%)\end{array}$ & $\begin{array}{l}\text { Breast-conserving } \\
\text { Surgery }(\%)^{¥}\end{array}$ \\
\hline Automated needle & 56 & 78 & 0 & 52 \\
\hline Directional vacuum-assisted & 56 & 84 & 0 & 14 \\
\hline
\end{tabular}

Tab. 2. Histologica diagnosis of automated needle and directional, vacuum-assisted biopsy specimens.

\begin{tabular}{lcc}
\hline & No. (\%) of Biopsies Performed Using \\
\hline Histological Diagnosis & $\begin{array}{c}\text { Automated } \\
\text { Needle }\end{array}$ & $\begin{array}{c}\text { Vacuum-assisted } \\
\text { Device }\end{array}$ \\
\hline Benign & $151(78)$ & $57(89)$ \\
Fibroadenoma & 2 & 2 \\
Papilloma & 1 & 3 \\
Benign nonspecific* & 148 & 52 \\
High-risk & $4(2)$ & $2(3)$ \\
Radial scar & 1 & 0 \\
Atypical ductal hyperplasia & 3 & 2 \\
Atypical lobular hyperplasia & 0 & 0 \\
Malignant & $28(15)$ & $5(8)$ \\
Ductal carcinoma in situ & 15 & 3 \\
Lobular carcinoma in situ & 0 & 1 \\
Invasive ductal carcinoma & 10 & 1 \\
Invasive lobular carcinoma & 3 & 0 \\
Insufficient sample obtained & $10(5)$ & 0 \\
* Diagnoses included fibrocystic change, ductal or lobular typical hyperplasia, apo- \\
crine metaplasia, sclerotic change, adenosis.
\end{tabular}

Tab. 3. categories of pathological interpretation of automated needle and vacuum-assisted biopsy (as specified in the European guidelines).

\begin{tabular}{|c|c|c|c|}
\hline $\begin{array}{l}\text { Category/ } \\
\text { Description }\end{array}$ & Examples & $\begin{array}{l}\text { Automated } \\
\text { Needle }\end{array}$ & $\begin{array}{c}\text { Vacuum-assisted } \\
\text { Device }\end{array}$ \\
\hline B1 Normal & $\begin{array}{l}\text { Normal tissue or } \\
\text { not interpretable }\end{array}$ & & \\
\hline $\begin{array}{l}\text { B2 Benign } \\
\text { lesion }\end{array}$ & $\begin{array}{l}\text { Fibrocystic change, } \\
\text { fibroadenoma, } \\
\text { sclerosing adenosis, } \\
\text { fat necrosis. }\end{array}$ & 160 & 54 \\
\hline $\begin{array}{l}\text { B3 Lesion } \\
\text { of uncertain } \\
\text { potential }\end{array}$ & $\begin{array}{l}\text { Papillary lesion, } \\
\text { radial scar } \\
\text { lobular intraepithelial } \\
\text { neoplasia, } \\
\text { atypical lobular } \\
\text { hyperplasia, } \\
\text { phyllodes tumor. }\end{array}$ & 2 & 3 \\
\hline $\begin{array}{l}\text { B4 Suspicious } \\
\text { of malignancy }\end{array}$ & $\begin{array}{l}\text { Atypical ductal } \\
\text { hyperplasia }\end{array}$ & 3 & 2 \\
\hline \multirow[t]{2}{*}{ B5 Malignant } & B5 a Malignant-in-situ & 15 & 4 \\
\hline & $\begin{array}{c}\text { B5 b Malignant } \\
\text { invasive }\end{array}$ & 13 & 1 \\
\hline
\end{tabular}

Based on these measurements, it appears the two biopsy techniques can be meaningfully compared.

According to European Guidelines for Quality Assurance in Breast Cancer Screening and Diagnosis (18), all breast needle biopsies should be classified to B1-B5 categories due to histopathological appearances. This classification of histological results is provided in the Table 3.
Tab. 4. Comparison of diagnostic accuracies of automated needle and directional, vacuum-assisted biopsy in DCIS.

\begin{tabular}{lcc}
\hline \multirow{2}{*}{ Surgical Diagnosis } & \multicolumn{2}{c}{ Diagnosis of DCIS after Biopsy (\%) } \\
\cline { 2 - 3 } & $\begin{array}{c}\text { Automated Needle } \\
\text { Biopsy }\end{array}$ & $\begin{array}{c}\text { Vacuum-assisted } \\
\text { Biopsy }\end{array}$ \\
\hline IDC & $4(27)$ & 0 \\
DCIS (or lesion gone) & $11(73)$ & $2(100)$ \\
\hline Total & $15(100)$ & $2(100)$ \\
\hline
\end{tabular}

Among the 193 lesions that had the stereotactic 14-gauge automated needle biopsy, 101 (52\%) had a subsequent surgical excision. In these 101 lesions, the stereotactic automated needle biopsy yielded benign findings in 62 (61\%), radial scar in 1 (1 $\%$ ), atypical ductal hyperplasia (ADH) in 3 (3\%), ductal carcinoma in situ (DCIS) in 15 (15\%), and infiltrating cancer, either invasive ductal carcinoma (IDC) or invasive lobular carcinoma (ILC) in 12 (12\%). Of 27 stereotactically proven cancers, surgery revealed cancer in 26 ; in one stereotactically proven cancer, stereotactic biopsy yielded ILC but surgery showed benign findings. Histological review of this case confirmed the presence of ILC in the stereotactic biopsy material, suggesting that the ILC was completely removed at stereotactic biopsy. No false-positive findings were encountered. The specificity rate for the automated needle biopsy was $100 \%$.

False-negative findings were encountered in 19 lesions. In 18 lesions with a benign histological diagnosis, the surgery recommended due to imaging-histological discordance revealed in situ malignancy in twelve (in one case papillary in situ carcinoma) and invasive cancer in six lesions (mucinous invasive cancer in one case).

In one lesion with a benign histologic diagnosis, an immediate second biopsy with the vacuum-assisted device yielded DCIS.

The stereotactic automated needle biopsy identified correctly 32 high-risk or malignant lesions with 19 missed cancers, which represents the sensitivity rate of the automated needle biopsy $0.627,(63 \%)$ and a negative predictive value 0.853 in this study.

Among the 64 lesions that had the stereotactic vacuum-assisted biopsy, $9(14 \%)$ had a subsequent surgical excision. In these 9 lesions, the stereotactic vacuum-assisted biopsy yielded benign findings in 3 (33\%), atypical ductal hyperplasia in $2(22 \%)$, ductal carcinoma in situ in $2(22 \%)$, lobular carcinoma in situ (LCIS) in $1(11 \%)$, and invasive ductal carcinoma in 1 (11\%).

In one patient with the histological diagnosis of low grade DCIS, the surgery was contradicted because of serious clinical condition and the biopsy was performed mainly to acquire imunohistochemical profile.

Of 5 stereotactically proven cancers, breast-conserving surgery 
Comparison of Underestimation Rates of Automated Needle and Vacuum-assisted Biopsy in DCIS Diagnosis

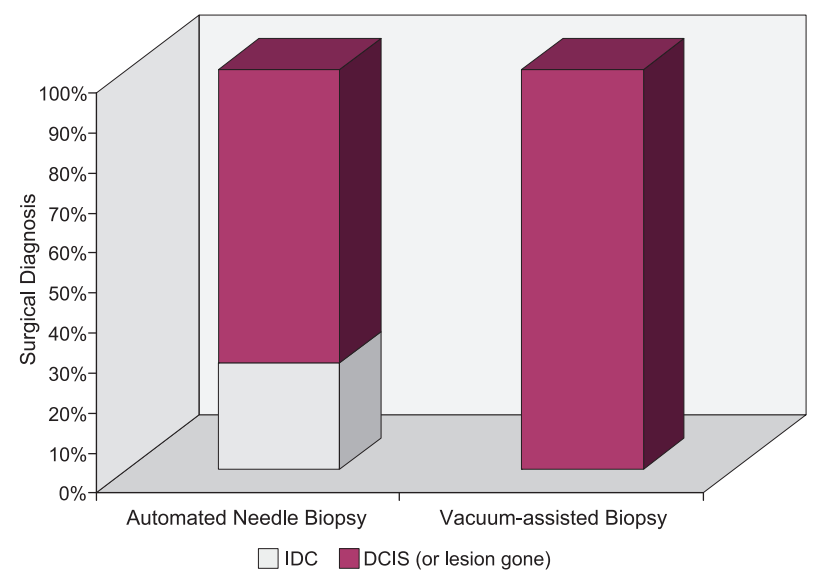

Fig. 1. Comparison of underestimation rates of automated needle and vacuum-assisted biopsy in DCIS diagnosis.

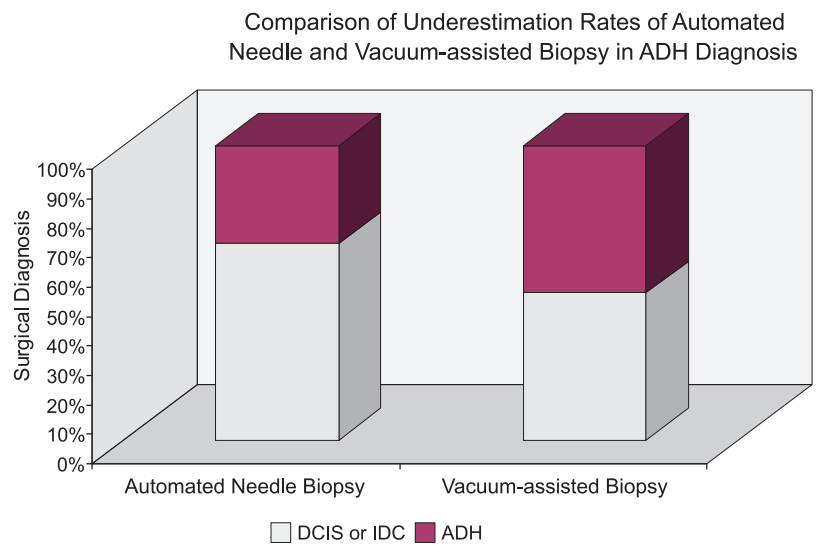

Fig. 2. Comparison of underestimation rates of automated needle and vacuum-assisted biopsy in ADH diagnosis.

$\mathrm{ADH}$ and DCIS Lesions Entirely Removed with Stereotactic Breast Biopsy

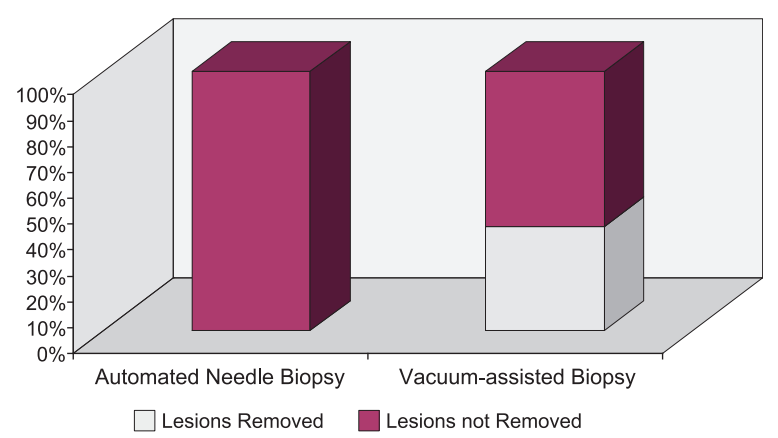

Fig. 3. ADH and DCIS lesions entirely removed with stereotactic breast biopsy.

was performed in four cases. The surgical histological diagnosis revealed cancer only in one case; in two cases the stereotactically proven cancers with histological diagnosis DCIS and in one case with IDC, the stereotactic vacuum-assisted biopsy completely removed suspicious clusters of microcalcifications and surgery showed only atypical ductal hyperplasia in one case of DCIS and benign finding and biopsy site change in two cases of IDC and DCIS, suggesting an entire removal with stereotactic biopsy. No false-positive findings were encountered with the specificity rate of vacuum-assisted biopsy of $100 \%$.

All ADH and DCIS stereotactic breast biopsy sites False-negative findings were encountered in one lesion. The missed cancer was mammographically evident as a cluster of pleomorphic calcifications. Calcifications were not identified at either specimen radiography or histological analysis; stereotactic biopsy yielded fat necrosis (the patient had previous trauma anamnesis) and surgical excision yielded infiltrating ductal carcinoma. The stereotactic vacuum-assisted biopsy correctly identified seven high-risk or malignant lesions with one missed cancer, which represented the sensitivity rate of vacuum-assisted biopsy $0,875,(87.5 \%)$ and a negative predictive value 0.977 in this study.

They were positively identified microscopically or both grossly and microscopically in the surgical lumpectomy or mastectomy specimens. The automated needle biopsy of DCIS lesions did not result in detection of invasive ductal carcinoma in four $(27 \%)$ of 15 specimens. None $(0 \%)$ of the 32 DCIS lesions, in which biopsy was performed with the directional, vacuum-assisted device, was determined to be invasive cancer at surgery. These differences are shown in Table 4 and Figure 1 and are non significant due to insufficient number of DCIS in the vacuum-assisted biopsy group at $p$ value of 0.404 (Fisher exact test).

$\mathrm{ADH}$ was determined at surgery to be DCIS or infiltrating ductal carcinoma in two (77\%) of 3 automated needle biopsy specimens and in one (50\%) of 2 directional, vacuum-assisted biopsy specimens of ADH lesions (Fig. 2). These differences are shown in Table 5 and are not significant at $\mathrm{p}$ value of 0.709 .

A complete excision (with clear margins) of ADH and DCIS lesions is compared for automated needle biopsy and directional, vacuum-assisted biopsy in the Table 6. ADH and DCIS lesions were percutaneously excised with clear margins in two (40\%)

Tab. 4. Comparison of diagnostic accuracies of automated needle and directional, vacuum-assisted biopsy in DCIS.

\begin{tabular}{lcc}
\hline \multirow{2}{*}{ Surgical Diagnosis } & \multicolumn{2}{c}{ Diagnosis of DCIS after Biopsy (\%) } \\
\cline { 2 - 3 } & $\begin{array}{c}\text { Automated Needle } \\
\text { Biopsy }\end{array}$ & $\begin{array}{c}\text { Vacuum-assisted } \\
\text { Biopsy }\end{array}$ \\
\hline IDC & $4(27)$ & 0 \\
DCIS (or lesion gone) & $11(73)$ & $2(100)$ \\
\hline Total & $15(100)$ & $2(100)$ \\
\hline
\end{tabular}

Tab. 5. Comparison of diagnostic accuracies of automated needle and directional, vacuum-assisted biopsy in ADH.

\begin{tabular}{lcc}
\hline \multirow{2}{*}{ Surgical Diagnosis } & \multicolumn{2}{c}{ Diagnosis of ADH after Biopsy (\%) } \\
\cline { 2 - 3 } & Automated Needle & Vacuum-assisted \\
& Biopsy & Biopsy \\
\hline DCIS or IDC & $2(77)$ & $1(50)$ \\
ADH & $1(33)$ & $1(50)$ \\
\hline Total & $3(100)$ & $2(100)$ \\
\hline
\end{tabular}


Tab. 6. ADH and DCIS lesions entirely removed with stereotactic breast biopsy.

\begin{tabular}{lcc}
\hline Biopsy & $\begin{array}{c}\text { Lesions Removed } \\
(\%)\end{array}$ & $\begin{array}{c}\text { Lesions not Removed } \\
(\%)\end{array}$ \\
\hline Automated Needle & 0 & $18(100)$ \\
Vacuum-assisted & $2(40)$ & $3(60)$ \\
\hline
\end{tabular}

Tab. 7. Analysis of complications during biopsy procedures and correlation with insufficient samples.

\begin{tabular}{lccccc}
\hline \multirow{2}{*}{ Complication } & \multicolumn{2}{c}{ Biopsy } & & \multicolumn{2}{c}{ Insufficient Sample } \\
\cline { 2 - 3 } \cline { 5 - 6 } & $\begin{array}{c}\text { Automated } \\
\text { Needle }\end{array}$ & $\begin{array}{c}\text { Vacuum- } \\
\text {-assisted }\end{array}$ & $\begin{array}{c}\text { Automated } \\
\text { Needle }\end{array}$ & $\begin{array}{c}\text { Vacuum- } \\
\text {-assisted }\end{array}$ \\
\hline Bleeding & 3 & 2 & & 1 & 0 \\
Nausea & 5 & 0 & & 0 \\
Syncope & 1 & 0 & & 0 \\
\hline
\end{tabular}

Pearson Correlation Coefficient (r): 0,8660

of 5 directional, vacuum-assisted biopsy specimens as compared to none of 18 automated needle biopsy specimens (Fig. 3 ) with a statistically significant difference at $p<0.05$, Fisher exact test.

The vacuum assisted biopsy completely removed $28 \%$ of all clusters of microcalcification in comparison to $0 \%$ of clusters removed by the automated needle biopsy with statistically significant difference. The number of surgical procedures performed in histologically benign lesions was also significantly lower in the VAB group (3/57) compared to the automated needle biopsy group (54/151).

Follow-up information was available for 69 of total 89 benign lesions biopsied with automated needle and for 41 (76\%) of total 54 benign lesions biopsied with vacuum-assisted device without subsequent surgery. The surgical procedure was recommended, but not performed in 3 lesions biopsied with automated needle and one lesion with vacuum-assisted biopsy due to interval changes in mammography. These cases were excluded from the follow-up analysis and sensitivity and negative predictive value evaluation. In 19 lesions biopsied with automated needle and 13 lesions with vacuum-assisted biopsy no follow up information was available. No delayed false negative cases have been identified to date.

The complication rate (Tab. 7) was low and similar in the two groups: $4.7 \%$ (9/193) for the automated needle biopsy and $3.1 \%$ $(2 / 64)$ for the vacuum-assisted biopsy with $p$ value of 0.598 (not significant).

Bleeding during the automated needle biopsy procedure occurred in three lesions. In two of these three lesions, the biopsy had to be terminated and in one lesion the sample was considered insufficient for an accurate histological diagnosis. Nausea as the reason of terminating the procedure occurred in 5 lesions, with two insufficient samples. Syncope occurred in one lesion with only three core sample obtained and considered insufficient by histopathologist. Two complications occurred during the procedure of the stereotactic vacuum-assisted biopsy; in one lesion the procedure was terminated because of bleeding but the sample was considered sufficient. In second lesion, the surgical intervention was required to stop the bleeding. No infection occurred after both procedures.
The samples were considered insufficient in $5 \%(10 / 193)$ of automated needle biopsy procedures. The surgery was recommended in 8 lesions, surgical diagnosis yielded benign changes in four lesions and in situ changes and invasive cancer both in two lesions. Follow-up mammography was recommended in two lesions, in one case with no interval change and once with no follow up data.

In four lesions with an insufficient sampling, the procedure had to be prematurely terminated due to complications. Complications correlation analysis with the insufficient samples showed a high degree of correlation with Pearson correlation coefficient 0.866 .

None insufficient sample occurred in the vacuum-assisted biopsy group.

\section{Discussion}

In recent years, needle localization and excisional biopsies have been largely replaced by image guided breast biopsies for the diagnosis of cancer. With the expansion of mammography and the widespread use of preoperative biopsy techniques, a new area of controversy has evolved. Biopsy techniques that only sample a portion of mammographic lesion will inevitably have less sensitivity then excisional biopsies.

The importance of accurate non-operative diagnosis cannot be underestimated. It enables the safe discharge of those patients with benign disease and the planning of correct surgery for those with malignancy (19).

The general sensitivity and specificity of stereotactically guided large core-needle breast biopsy is high, even for microcalcifications. In our study, the sensitivity was $63 \%$ for the automated needle biopsy and $87.5 \%$ for the vacuum-assisted device. The false-negativity rate of $12.5 \%$ for the vacuum-assisted biopsy was higher then previously reported. This was due to one missed cancer, in which case calcifications were not identified at either specimen radiography or histological analysis. A failure to identify calcifications on specimen radiograph has been previously shown to correlate with nondiagnostic results at stereotactic biopsy (20). Failure to retrieve calcification occured in $14 \%$ of CB and $1 \%$ of VAB (21). A false-negative rate of up to $74 \%$ has been reported when no calcification was evident on the specimen radiograph (22). The identification of calcifications at histological analysis in the absence of calcifications on the specimen radiographs is usually not adequate, because calcifications may be seen microscopically in lesions that lack calcifications on the mammogram $(23,24)$.

Consequently, if no calcium is identified on the radiograph of specimen cores, then the management of choice is either a repeat biopsy or diagnostic excision. An early interval screening should not be considered as a satisfactory alternative in patient management (25).

The key to accurately asses a mammographic lesion is the evaluation of an adequate tissue volume. The larger sample volumes produced by VAB devices allow more extensive sampling and even a complete removal of some clusters of microcalcifications. Kettritz et al (26) in a trial involving 2,874 patients in five centers using $11-\mathrm{G}$ VAB removed $76 \%$ of clusters measuring less 
than $10 \mathrm{~mm}$ and even removed $30 \%$ of clusters measuring $11-20$ $\mathrm{mm}$ in diameter. If a cluster of calcification has been adequately sampled and the pathologist finds benign changes associated with visible calcification, the patient can be discharged without further intervention (18). In our study, vacuum assisted biopsy removed $28 \%$ of all clusters of microcalcification and the number of unnecessary surgical procedures in benign lesions was significantly lower in the VAB group.

In addition, $40 \%$ of the directional, vacuum-assisted biopsy procedures removed all of the ADH and DCIS from the breast with histologically clean margins.

The diagnosis and management of those lesions, which are frequently small and of borderline malignant potential, presents the greatest tests of radiological and pathological skill (18). Any biopsy technique that only samples a portion of lesion will remain a challenge for the pathologist. A continuous spectrum of proliferative changes exists between $\mathrm{ADH}$, low-grade DCIS, high-grade DCIS and microinvasive ductal carcinoma. Lesions fulfilling the definition of DCIS but having an aggregate diameter less then 2 $\mathrm{mm}$ are defined as $\mathrm{ADH}$ (27).

If the pathologist is provided with only limited tissue to analyze, it may be impossible to identify an adequate volume of neoplastic change to make a diagnosis of DCIS (14).

In our study, the underestimation rate of ADH to DCIS was $77 \%$ by the automated needle biopsy and $50 \%$ by the vacuum-assisted biopsy, which is higher than current data published (28-30). The underestimation rate of DCIS to IDC of $27 \%$ by automated needle biopsy and $0 \%$ by vacuum-assisted biopsy is similar (or lower for VAB) to the data previously published (14). Evidence exists that total removal of the index microcalcification correlates with decreased pathological upgrade rates at surgery (31).

The most up to date review of stereotactically guided breast biopsy suggests that a high degree of diagnostic accuracy and hence safe patient care can only be achieved by meticulous attention to technique and multi-disciplinary cooperation (32).

The complication rate was low and similar for both methods, with a high degree of correlation between insufficient samples obtained and complications during the procedure of automated needle biopsy.

In conclusion, the vacuum-assisted biopsy outperformed the 14-gauge automated needle biopsy with a lower disease underestimation rate, sensitivity and false-negative rates; however these differences were not statistically significant due to small data files and relatively small number of identified malignant lesions in the vacuum-assisted biopsy group. This may be related to the restricted selection of vacuum-assisted method until June 2010, to sample only microcalcifications of benign or semi-malignant mammographic appearance.

The vacuum-assisted biopsy completely removed significantly more clusters of microcalcifications in comparison to the automated needle biopsy, which significantly reduced the need for surgery in benign lesions.

\section{References}

1. Ondrušová M, Pleško I, Safaei-Diba Ch, Obšitníková A, Štefaňáková D, Ondruš D. Komplexná analýza výskytu a úmrtnosti na zhubné nádory v Slovenskej republike [online]. Bratislava, Národný onkologický register SR, NCZI, 2007 (cit. 24.2.2009). http://www.nor-sk.org/.

2. Brem RF, Behrndt VS, Sanow L, Gatewood OMB. Atypical ductal hyperplasia: histologic underestimation of carcinoma in tissue harvested from impalpable breast lesions using 11-gauge stereotactically guided directional vacuum-assisted biopsy. AJR 1999; 172: 1405-1407.

3. Gadzala DE, Cederbom GJ, Bolton JS, McKinnon WM, Farr GH, Champaign J et al. Appropriate management of atypical ductal hyperplasia diagnosed by stereotactic core needle breast biopsy. Ann Surg Oncol 1997; 4 (4): 283-286.

4. Tocino I, Garcia BM, Carter D. Surgical biopsy findings in patients with atypical hyperplasia diagnosed by stereotaxic core needle biopsy. Ann Surg Oncol 1996; 3 (5): 483-492.

5. Dahlstrom JE, Jain S, Sutton T, Sutton S. Diagnostic accuracy of stereotactic core biopsy in a mammographic breast cancer screening programme. Histopathology 1996; 28 (5): 421-427.

6. Jackman RJ, Nowels KW, Shepard MJ, Finkelstein SI and Marzoni FA Jr. Stereotaxic large-core needle biopsy of 450 nonpalpable breast lesions with surgical correlation in lesions with cancer or atypical hyperplasia. Radiology 1994; 193: 91-95.

7. Liberman L, Cohen LA, Dershaw DD, Abramson AF, Hann LE, Rosen PP. Atypical ductal hyperplasia diagnosed at stereotaxic core biopsy of breast lesions:an indication for surgical biopsy. AJR 1995; 164: 1111-1113.

8. Liberman L, Dershaw DD, Rosen PP et al. Stereotaxic core biopsy of breast carcinoma: accuracy at predicting invasion. Radiology 1995; 194: 379-381.

9. Berg WA. When is core breast biopsy or fine-needle aspiration not enough? (editorial) Radiology 1996; 198: 313-315.

10. Dershaw DD, Caravella BA, Liberman L. Limitations and compications in the utilization of stereotaxic core breast biopsy. Breast J 1996; 2: $13-17$.

11. Dershaw DD, Moris EA, Liberman L, Abramson AF. Nondiagnostic stereotaxic core breast biopsy: results of rebiopsy. Radiology 1996; 198: 323-325.

12. Burbank F. Stereotactic breast biopsy of atypical ductal hyperplasia and ductal carcinoma in situ lesions: improved accuracy with directional, vacuum-assisted biopsy. Radiology 1997; 202: 843-847.

13. Jackman RJ, Burbank F, Parker SH et al. Atypical ductal hyperplasia diagnosed at stereotactic breast biopsy: improved reliability with 14-gauge, directional, vacuum-assisted biopsy. Radiology 1997; 204: 485-488.

14. Jackman RJ, Parker SH, Evans III WP et al. Stereotactic breast biopsy of nonpalpable lesions: determinants of ductal carcinoma in situ underestimation rates. Radiology 2001; 218: 497-502.

15. Meyer JE, Smith DN, Di Piro PJ et al. Stereotactic breast biopsy of clustered microcalcification with a directional, vacuum-assisted device. Radiology 1997; 204: 575-576.

16. Won B, Reynolds HE, Lazaridis CL, Jackson V. Stereotactic biopsy of DCIS of the breast using an 11-gauge vacuum-assisted device: persistent underestimation of disease. AJR 1999; 173: 227-229. 
17. Philpotts LE, Lee CH, Horvath LJ et al. Underestimation of breast cancer with 11-gauge vacuum suction biopsy. AJR 2000; 175: 1047-1050.

18. Perry $\mathbf{N}$ et al. European guidelines for quality assurance in breast cancer screening and diagnosis, 4th edn, 20067. www.euref.org/ ND7306954ENC_002.pdf.

19. Wallis MG, Cheung S, Kearins O, Lawrence MG et al. Non-operative diagnosis - effect on repeat-operation rates in UK breast screening programme. Eur Radiol 2009; 19: 318-323.

20. Liberman L, Evans WP III, Dershaw DD et al. Radiography of microcalcifications in stereotaxic mammary core biopsy specimens. Radiology 1994; 190: 223-225.

21. Jackman RJ, Rodriguez-Soto $\mathbf{J}$ et al. Breast microcalcifications: retrieval failure at prone stereotactic core and vacuum breast biopsy- frequency, causes, and outcome. Radiology 2006; 239: 61-70.

22. Bagnall MJ, Evans AJ, Wilson et al. When have mammographic calcifications been adequately sampled at needle core biopsy? Clin Radiol 2000; 55: 548-553.

23. Stomper PC, Davis SP, Weidner N, Meyer JE. Clinically occult, noncalcified breast cancer: serial radiologic-pathologic correlation in 27 cases. Radiology 1988; 169: 621-626.

24. Dahlstrom JE, Sutton S, Jain S. Histologic-radiologic correlation of mammographically detected microcalcification in stereotactic core biopsies. Am J Surg Pathol 1998; 22: 256-259.

25. NHS Breast Screening Programme, Clinical guidelines for breast cancer screening assessment, 3rd ed, 2010 ISBN978-1-84463-068-04. Available via www.cancerscreening.nhs.uk/breastscreen/publications/ nhsbsp49.html.
26. Laurenco AP, Mainiero MB, Lazarus E, Giri D, Schepps B et al. Stereotactic breast biopsy: comparison of histologic underestimation rates with 11- and 9-gauge vacuumassisted breast biopsy. AJR Am J Roentgenol 2007; 189: W275-279.

27. Brem RF, Schoonjans JM, Goodman SN et al. Nonpalpable breast cancer: percutaneous diagnosis with 11- and 8-gauge stereotactic vacuumassisted biopsy device. Radiology 2001; 219: 793-796.

28. Darling ML et al. Atypical ductal hyperplasia and ductal carcinoma in situ as revealed by large-core needle breast biopsy: results of surgical excision. AJR 2000; 175: 1341-1346.

29. Houssami $\mathbf{N}$ et al. Borderline breast core needle histology: predictive values for malignancy in lesions of uncertain malignant potential (B3). $\mathrm{Br}$ J Cancer 2007; 96: 1253-1257.

30. Pandelidis S, Heiland D, Jones D, Stough K, Trapeni J, Suliman Y. Accuracy of 11-gauge vacuum-assisted core biopsy of mammographic breast lesions. Ann Surg Oncol 2003; 10 (1): 43-47.

31. Penco $\mathbf{S}$ et al. Stereotactic vacuum-assisted breast biopsy is not not a therapeutic procedure even when all mammographicallyy found microcalcifications are removed: analysis of 4,086 procedures. AJR 2010; 195: $1255-1260$.

32. Ames V, Britton PD. Stereotacticall guided breast biopsy: a review. Insights into Imagining 2011: 1-6.

Received March 15, 2011. Accepted August 18, 2012. 